\title{
An improved MCDM method for maintenance approach selection: A case study of auto industry
}

\author{
Milad Aghaee and Safar Fazli
}

Faculty of Social Science, Department of Industrial Management, Imam Khomeini University, Qazvin, Iran

\begin{tabular}{l}
\hline A R T I C L E I N F O \\
\hline Article history: \\
Received July 25, 2011 \\
Received in Revised form \\
September, 10, 2011 \\
Accepted 12 September 2011 \\
Available online \\
18 September 2011 \\
\hline Keywords: \\
Maintenance strategy \\
Multi-criteria decision making \\
Analytic network process (ANP) \\
Decision making trial and \\
evaluation laboratory \\
(DEMATEL)
\end{tabular}

\section{A B S T R A C T}

\begin{abstract}
In the current competitive environment, managers have been making attempts to convert organizations under their supervision into competitive and responsive through creating capability of timely delivery of quality products and services. In line with this, maintenance as a system plays an important role in achieving these goals. The maintenance strategy selection is a kind of multiple criteria decision-making (MCDM) problem, which requires considering a large number of complex factors as multiple evaluation criteria. A robust MCDM method should consider the interactions among criteria. The analytic network process (ANP) is a relatively new MCDM method, which can deal with all kinds of interactions systematically. Moreover, the Decision Making Trial and Evaluation Laboratory (DEMATEL) not only can convert the relations between cause and effect of criteria into a visual structural model, but also can be used as a way to handle the inner dependences within a set of criteria. Hence, this paper proposes an effective solution based on a combined ANP and DEMATEL approach to help vehicle companies that need to evaluate and select maintenance strategies.
\end{abstract}

(C) 2012 Growing Science Ltd. All rights reserved.

\section{Introduction}

The global competition characterized by both a technology push and a market pull has forced the companies across the globe to achieve world-class performance through continuous improvement in their products and processes (Kumar and Kumar, 2005). So, manufacturing environments have recently changed so fast so that manufacturing system competitiveness has increased. In an effort to compete with other firms in the global marketplace, manufacturing firms have been investing a lot to improve their manufacturing performance in terms of cost, quality, and flexibility, (Karsak, 2001). On the other hand, Manufacturing firms face great pressure to reduce their production costs, continuously. One of the main expenditure items for the firms is maintenance cost, which can reach $15-70 \%$ of production costs, varying according to the type of industry (Bevilacqua \& Braglia, 2000). On the other hand, one third of all maintenance costs are wasted as the result of unnecessary or improper maintenance activities (Mobley, 2002). Unfortunately, unlike production and

\footnotetext{
* Corresponding author. Tel: +0982188872548

E-mail addresses: milad_aghaee1365@yahoo.com(M. Aghaee) 
manufacturing problems maintenance received little attention in the past. Today, the role of maintenance is changing from a "necessary evil" to a "profit contributor" and towards a "partner" of companies to achieve world-class competitiveness (Waeyenbergh \& Pintelon, 2002). Therefore, research on maintenance represents an opportunity for making significant contribution by academics.

Maintenance can be categorized into two different types of corrective and preventive (Li \& Khoo, 2006). Corrective maintenance is one which occurs after systems failure, and it covers all actions resulting from failure. Preventive maintenance is the maintenance performed prior to systems failure to retain equipment in specified circumstances (Swanson, 2001). Selection of optimum maintenance strategy is a type of MCDM problem, which can highly influence on the manufacturing expenditures. Because, maintenance plays vital role in keeping availability and reliability levels, product quality, and safety requirements and selection of best maintenance policy is important as the maintenance management is complex and the output of maintenance is hard to measure and quantify (Mechefske \& Wang, 2001).

Many conventional MCDM techniques are based on the additive idea along with the independence assumption, but each individual criterion is not often independent (Leung et al., 2003; Shee et al., 2003). To solve the interactions among elements, the analytic network process (ANP) as a relatively new MCDM method was introduced by Saaty (1996). The ANP is a mathematical theory, which deals with all kinds of dependence systematically (Saaty, 2004). The ANP has been successfully implemented in many areas (Agarwal \& Shankar, 2002; Chung et al., 2005; Coulter \& Sarkis, 2005; Kahraman et al., 2006; Karsak et al., 2003; Lee \& Kim, 2001; Meade \& Presley, 2002; Niemira \& Saaty, 2004; Partovi, 2001; Partovi \& Corredoira, 2002; Partovi, 2006; Shang et al., 2004; Tesfamariam \& Lindberg, 2005; Yurdakul, 2004). However, the treatments of inner dependences in those ANP works may suffer from some issues, which motivates us to use Decision Making Trial and Evaluation Laboratory (DEMATEL) method (Gabus \& Fontela, 1972, 1973; Fontela \& Gabus, 1976; Hori \& Shimizu, 1999).

On the other hand, there are some researches by different techniques about selection of maintenance strategy (Alnajar \& alsyuof, 2003; Martorell et al., 1999; Wang \& Hayfield, 1999; Yang et al., 1999; Sharma \& Kumar, 2005; Shygith et al, 2008; Bashiri et al, 2011; Mardani, 2010; Wang et al., 2007), but there is no research in the field of maintenance strategy selection with this technique and especially in vehicle industry. As the ANP and the DEMATEL have so many advantages, this paper proposes an effective solution based on an integrated ANP and DEMATEL approach to help vehicle industry companies select a favorable maintenance strategy.

The rest of this paper is organized as follows. In Section 2, a literature review is presented, In Section 3, evaluation methods are presented. In Section 4, an empirical study in vehicle industry is illustrated. Finally, according to the findings of this research, conclusions and suggestions are depicted.

\section{Literature review}

Six alternative maintenance strategies considered in this paper are introduced as following:

\subsection{Corrective maintenance}

Corrective, fire-fighting or breakdown maintenance strategy is used when the corrective maintenance strategy is applied until failure occurs (Swanson, 2001; Waeyenbergh \& Pintelon, 2002; Mechefske \& Wang, 2003). It is considered as a feasible strategy in the events where profit margins are significant (Sharma et al., 2005). However, such a firefighting mode of maintenance often causes destruction on related facilities, personnel and environment.

\subsection{Time-based preventive maintenance}

According to reliability characteristics of equipment, maintenance is performed in definite periods to reduce frequent and sudden failure. This maintenance strategy is often called time-based preventive 
maintenance. For performing time-based preventive maintenance, we need to have a decision support system and it is often difficult to define the most effective maintenance intervals (Mann et al, 1995). There are, however, many cases when time-based maintenance strategies are implemented and most machines are maintained with a substantial amount of useful life remaining (Mechefske \& Wang, 2003).

\subsection{Condition-based maintenance}

Maintenance decision normally depends on the measured information from a set of sensors system when using the condition-based maintenance strategy. There are literally various techniques are available, such as vibration monitoring, lubricating analysis, and ultrasonic testing. The monitored data of equipment parameters could tell engineers whether the situation is normal, allowing the maintenance employee to use necessary maintenance before failure occurs. This maintenance strategy is normally designed for rotating machines, e.g. turbines, centrifugal pumps and compressors. However, limitations in data coverage and quality reduce the effectiveness and accuracy of the condition-based maintenance strategy (Al-Najjar \& Alsyouf, 2003).

\subsection{Predictive maintenance}

Predictive maintenance often refers to the same maintenance strategy with condition-based maintenance (Sharma et al., 2005; Mobley, 2002). In this paper, considering the recent development of fault prognosis techniques (Bengtsson, 2004; Byington et al, 2002), predictive maintenance is used to represent the maintenance strategy that is able to forecast the temporary trend of performance degradation and predict faults of machines by analyzing the monitored parameters data. Fault prognostics is a young technique employed by maintenance management, which gives maintenance engineers the possibility to plan maintenance based on the time of future failure and coincidence maintenance activities with production plans, customers' orders and personnel availability. Recently, the intelligent maintenance system was described by Djurdjanovic et al (2003), focusing on fault prognostic techniques and aiming to achieve near-zero-downtime performance of equipment.

\subsection{Total productive maintenance (TPM)}

TPM defined by Nakajima (1988) incorporates a company-wide technique to plant, equipment or asset care, which involves the active participation from top management to workers on the floor to reach equipment effectiveness by removing the six big losses such as downtime losses, set-up and adjustments losses; speed losses; reduced speed; defect losses and reduced yield. In TPM, the practice of PM is integrated with the idea of total quality through employee involvement (TQEI). Operators maintain their own machines by practicing $5 \mathrm{~S}$ principles. They compile and interpret maintenance and operating data of their machines that helps to identify signs of deterioration, if any. Routine daily maintenance checks, minor adjustments, lubrication, and minor part changes are the activities performed by the operators. TPM seeks to improve the overall equipment effectiveness (OEE), which is an important indicator, used to measure TPM. An overall 85 percent of OEE is considered as world class and a benchmark for others (Blanchard, 1997; McKone et al., 1999; Chand and Shirvani, 2000).

\section{Evaluation method}

In this section, some essentials of the ANP and the DEMATEL are briefly explained.

\subsection{The ANP}

The maintenance system strategy selection is an MCDM problem since it involves various criteria. There are several MCDM methods developed, such as the elimination and choice translating reality 
(ELECTRE), the technique for order preference by similarity to ideal solution (TOPSIS), and the analytic hierarchy process (AHP). However, these methods do not deal with the interdependences among elements. For dealing with the interdependences among elements, the ANP as a new MCDM method was proposed by Saaty(1996).

Saaty (1999) has demonstrated several kinds of ANP models, such as the Hamburger Model, the Car Purchase BCR model, and the National Missile Defense model. However, from the viewpoint of Kinosita (2003), the ANP may simply be differentiated into two practical kinds of models: the Feedback System model and the Series System model (similar to the AHP model). In the Feedback System model, clusters link one by one in turn as a network system. This kind of model can capture effectively the complex effects of interplay in human society, especially when risk and uncertainty are involved (Saaty, 2003). However, it is usually hard to obviate the possibility of interactions within the criteria cluster. Thus, this paper suggests a modified Feedback System model (Fig. 1) that allows inner dependences within the criteria cluster, in which the looped arc signifies the inner dependences.

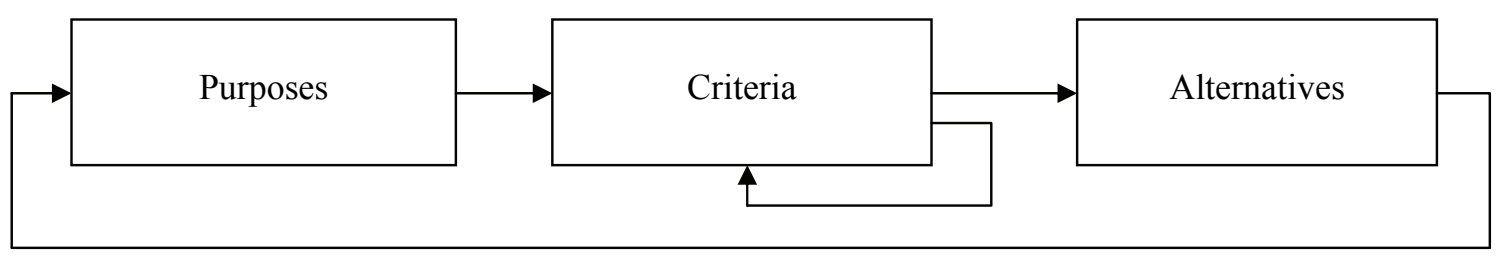

Fig.1. Feedback system model

In order to determine the relative importance between elements, decision makers are asked to respond through a series of pair-wise comparisons. These pair-wise comparisons are based on the Saaty's nine-point scale ranging from 1 (equal) to 9 (extreme). For evaluating the weights of elements, the AHP uses the principal eigenvector of comparison matrix, whereas the ANP employs the limiting process method of the powers of the super-matrix (Sekitani \& Takahashi, 2001). For synthesizing overall priorities for the alternatives, it requires adjusting the un-weighted super-matrix to keep it to be column stochastic (Sarkis, 1999). Then, the weighted super-matrix (the adjusted un-weighted super-matrix) can be raised to limit powers to calculate the overall priorities. However, before forming the un-weighted super-matrix, the treatment of inner dependences needs to employ the DEMATEL. The treatment of inner dependences can theoretically use the ANP, but another alternative is to use the DEMATEL.

\subsection{The DEMATEL}

The Battelle Memorial Institute conducted a DEMATEL method project through its Geneva Research Centre (Gabus \& Fontela, 1972, 1973). DEMATEL has become popular in many countries such as Japan since it is a comprehensive technique for creating and analyzing a structural model involving causal relationships among complex factors.

The DEMATEL is based on digraphs, which can separate involved factors into cause group and effect group. In order to apply the DEMATEL smoothly, this paper refines the version used by Fontela and Gabus (1976) and proposes four main steps as below.

Step 1: Generating the direct-relation matrix by measuring the relationship between criteria in four levels: 0 (no influence), 1 (very low influence), 2 (low influence), 3 (very high influence) and 4 (very high influence). Next, experts make sets of the pair-wise comparisons in terms of influence and direction between criteria. Then, as the result of these evaluations, the initial information can be prepared as the direct-relation matrix, which is an $n \times n$ matrix $\mathrm{A}$, in which $a_{i j}$ is denoted as the degree to which the criterion $i$ affects the criterion $j$.

Step 2: Normalizing the direct-relation matrix. On the base of the direct-relation matrix A, the normalized direct-relation matrix X can be obtained as follows, 


$$
\begin{aligned}
& X=k . A \\
& k=\frac{1}{\max \sum_{1 \leq i \leq n}^{n}{ }_{j=1} a_{i j}}, i, j=1, \cdots, n .
\end{aligned}
$$

Step 3: Attaining the total-relation matrix. Once the normalized direct-relation matrix $X$ is obtained, the total relation matrix $T$ is calculated as follows,

$T=X(I-X)^{-1}$

where $I$ is identity matrix.

Step 5: Set a threshold value and obtain the network relationship map (NRM). In order to explain the structural relation among the criteria and keep the complexity of the system to a manageable level at the same time, it is necessary to set a threshold value $p$ to filter out some negligible effects in matrix $\mathrm{T}$. Only some criteria, whose effect in matrix $\mathrm{T}$ is greater than the threshold value, should be chosen and shown in a network relationship map (NRM) for influence (Tzeng et al., 2007).In this paper, experts decided the threshold value is arithmetic mean of $T$ matrix numbers.

\section{Empirical study and discussion}

In this section, an empirical study in vehicle industry is presented to illustrate the application of the proposed solution for evaluating and selecting optimized maintenance strategy. A committee with 10 experts followed the proposed solution with the four-phase procedure. First, they defined the decision goal for selecting a favorable maintenance system strategy. In phase 2, after conducting the literature review and a profound discussion, three evaluation clusters were used to select an optimized maintenance system strategy. Specifically, the "Purposes" cluster involved one purpose of optimized maintenance strategy $(\mathrm{P})$; the "Criteria" cluster contained four criteria: security requirements $(\mathrm{C} 1)$, cost requirements $(\mathrm{C} 2)$, strategic requirements $(\mathrm{C} 3)$ and technical requirements $(\mathrm{C} 4)$; and the "Alternatives"' cluster comprised six maintenance system strategies: CM (A1), PM (A2), TPM (A3), RCM (A4), CBM (A5) and PDM (A6). In phase 3, the Feedback System model was used (Fig. 1), and then the decision structure (Fig. 2) was shaped for evaluating optimized maintenance system strategies, in which looped arcs indicate that inner dependences are to be handled by the DEMATEL.

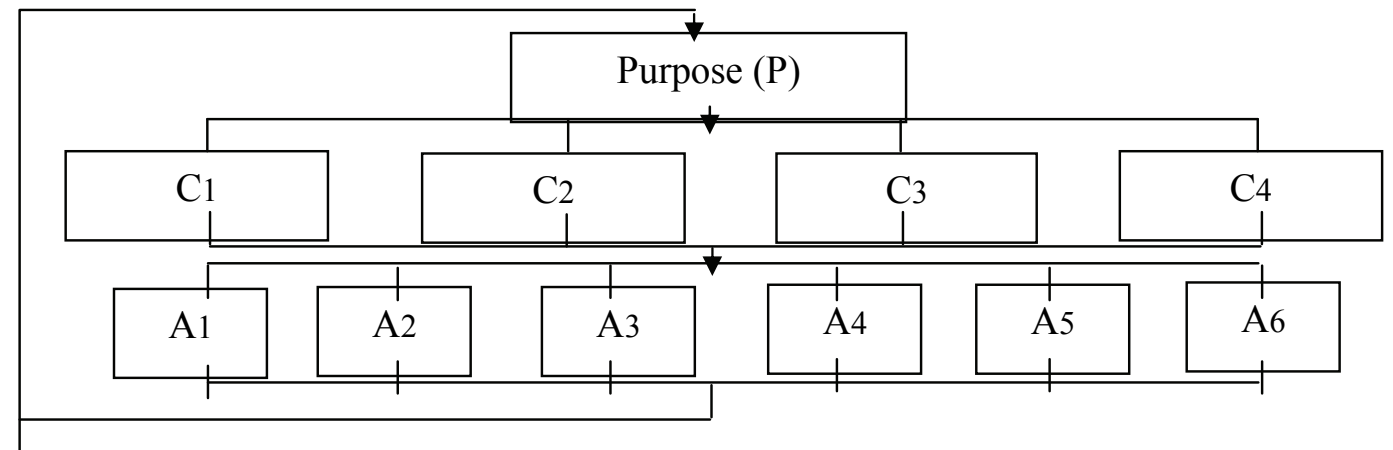

Fig.2. decision structure for the optimized maintenance system strategy

In phase 4 , for obtaining the relative influence between elements, the members of committee were asked to respond through a series of pair-wise comparisons. In order to aggregate their assessments, 
the geometric mean method was for the ANP and DEMATEL. After the aggregation, the directrelation matrix (Table 1) can be obtained, hereby the inner dependence matrix (Table 2) can be acquired by using the DEMATEL, and the un-weighted super matrix can be formed as shown in Table 3. The calculations of the super-matrix can be easily solved by using the professional software named "Super Decisions", and then the overall priorities were obtained from the limit super-matrix (see Table 4): $\mathrm{WC}=(\mathrm{C} 1, \mathrm{C} 2, \mathrm{C} 3, \mathrm{C} 4)=(0.000,0.227,0.092,0.180), \mathrm{WA}=(\mathrm{A} 1, \mathrm{~A} 2, \mathrm{~A} 3, \mathrm{~A} 4, \mathrm{~A} 5$, A6) $=(0.043,0.080,0.125,0.110,0.065,0.074)$.

Therefore, the most important criterion was C2 (Top management support) due to the highest priority of 0.227; and the desired alternative was Strategy A3 (Personalization strategy) due to the highest priority of 0.125 .

Table 1

Direct- relationship matrix

\begin{tabular}{lcccc}
\hline & $\mathrm{C} 1$ & $\mathrm{C} 2$ & $\mathrm{C} 3$ & $\mathrm{C} 4$ \\
\hline $\mathrm{C} 1$ & 0 & 0.395 & 0.385 & 0.220 \\
$\mathrm{C} 2$ & 0.240 & 0 & 0.266 & 0.294 \\
$\mathrm{C} 3$ & 0.208 & 0.330 & 0 & 0.240 \\
$\mathrm{C} 4$ & 0.120 & 0.266 & 0.218 & 0 \\
\hline
\end{tabular}

Table 2

The inner dependence matrix

\begin{tabular}{lcccc}
\hline & $\mathrm{C} 1$ & $\mathrm{C} 2$ & $\mathrm{C} 3$ & $\mathrm{C} 4$ \\
\hline $\mathrm{C} 1$ & 0.734 & 1.734 & 1.280 & 1.100 \\
$\mathrm{C} 2$ & 0.791 & 0.913 & 1.028 & 0.983 \\
$\mathrm{C} 3$ & 0.762 & 1.145 & 0.802 & 0.937 \\
$\mathrm{C} 4$ & 0.585 & 0.927 & 0.820 & 0.598 \\
\hline
\end{tabular}

Table 3

The un-weighted super matrix

\begin{tabular}{|c|c|c|c|c|c|c|c|c|c|c|c|}
\hline & $\mathrm{A} 1$ & A2 & A3 & A4 & A5 & A6 & $\mathrm{C} 1$ & $\mathrm{C} 2$ & $\mathrm{C} 3$ & $\mathrm{C} 4$ & Selection \\
\hline A1 & 0.0000 & 0.0000 & 0.0000 & 0.0000 & 0.0000 & 0.0000 & 0.10814 & 0.10721 & 0.06861 & 0.07157 & 0.00000 \\
\hline $\mathrm{A} 2$ & 0.0000 & 0.0000 & 0.0000 & 0.0000 & 0.0000 & 0.0000 & 0.19351 & 0.16938 & 0.13210 & 0.16668 & 0.00000 \\
\hline A3 & 0.0000 & 0.0000 & 0.0000 & 0.0000 & 0.0000 & 0.0000 & 0.21791 & 0.25791 & 0.21722 & 0.25796 & 0.00000 \\
\hline A4 & 0.0000 & 0.0000 & 0.0000 & 0.0000 & 0.0000 & 0.0000 & 0.22093 & 0.21305 & 0.24151 & 0.12816 & 0.00000 \\
\hline A5 & 0.0000 & 0.0000 & 0.0000 & 0.0000 & 0.0000 & 0.0000 & 0.12626 & 0.12085 & 0.15771 & 0.15276 & 0.00000 \\
\hline A6 & 0.0000 & 0.0000 & 0.0000 & 0.0000 & 0.0000 & 0.0000 & 0.13682 & 0.13160 & 0.18285 & 0.00000 & 0.00000 \\
\hline $\mathrm{C} 1$ & 0.0000 & 0.0000 & 0.0000 & 0.0000 & 0.0000 & 0.0000 & 0.00000 & 0.00000 & 0.00000 & 1.00000 & 0.49583 \\
\hline $\mathrm{C} 2$ & 0.0000 & 0.0000 & 0.0000 & 0.0000 & 0.0000 & 0.0000 & 0.21710 & 0.00000 & 0.50323 & 0.00000 & 0.11658 \\
\hline $\mathrm{C} 3$ & 0.0000 & 0.0000 & 0.0000 & 0.0000 & 0.0000 & 0.0000 & 0.37259 & 0.40476 & 0.00000 & 0.00000 & 0.17522 \\
\hline $\mathrm{C} 4$ & 0.0000 & 0.0000 & 0.0000 & 0.0000 & 0.0000 & 0.0000 & 0.41031 & 0.59524 & 0.49677 & 0.00000 & 0.21237 \\
\hline Selection & 0.0000 & 0.0000 & 0.0000 & 0.0000 & 0.0000 & 0.0000 & 0.00000 & 0.00000 & 0.00000 & 0.00000 & 0.00000 \\
\hline
\end{tabular}

Table 4

The limit matrix

\begin{tabular}{llllllllllll}
\hline & $\mathrm{A} 1$ & $\mathrm{~A} 2$ & $\mathrm{~A} 3$ & $\mathrm{~A} 4$ & $\mathrm{~A} 5$ & $\mathrm{~A} 6$ & $\mathrm{C} 1$ & $\mathrm{C} 2$ & $\mathrm{C} 3$ & C4 & Selection \\
\hline $\mathrm{A} 1$ & 0.0000 & 0.0000 & 0.0000 & 0.0000 & 0.0000 & 0.0000 & 0.04361 & 0.04361 & 0.04361 & 0.04361 & 0.04361 \\
$\mathrm{~A} 2$ & 0.0000 & 0.0000 & 0.0000 & 0.0000 & 0.0000 & 0.0000 & 0.08077 & 0.08077 & 0.08077 & 0.08077 & 0.08077 \\
$\mathrm{~A} 3$ & 0.0000 & 0.0000 & 0.0000 & 0.0000 & 0.0000 & 0.0000 & 0.12522 & 0.12522 & 0.12522 & 0.12522 & 0.12522 \\
$\mathrm{~A} 4$ & 0.0000 & 0.0000 & 0.0000 & 0.0000 & 0.0000 & 0.0000 & 0.11092 & 0.11092 & 0.11092 & 0.11092 & 0.11092 \\
$\mathrm{~A} 5$ & 0.0000 & 0.0000 & 0.0000 & 0.0000 & 0.0000 & 0.0000 & 0.06514 & 0.06514 & 0.06514 & 0.06514 & 0.00000 \\
$\mathrm{~A} 6$ & 0.0000 & 0.0000 & 0.0000 & 0.0000 & 0.0000 & 0.0000 & 0.07434 & 0.07434 & 0.07434 & 0.07434 & 0.00000 \\
C1 & 0.0000 & 0.0000 & 0.0000 & 0.0000 & 0.0000 & 0.0000 & 0.00000 & 0.00000 & 0.00000 & 0.00000 & 0.49583 \\
C2 & 0.0000 & 0.0000 & 0.0000 & 0.0000 & 0.0000 & 0.0000 & 0.22716 & 0.22716 & 0.22716 & 0.22716 & 0.11658 \\
C3 & 0.0000 & 0.0000 & 0.0000 & 0.0000 & 0.0000 & 0.0000 & 0.09195 & 0.09195 & 0.18089 & 0.18089 & 0.17522 \\
C4 & 0.0000 & 0.0000 & 0.0000 & 0.0000 & 0.0000 & 0.0000 & 0.18089 & 0.18089 & 0.00000 & 0.00000 & 0.21237 \\
\hline Selection & 0.0000 & 0.0000 & 0.0000 & 0.0000 & 0.0000 & 0.0000 & 0.00000 & 0.00000 & 0.00000 & 0.00000 & 0.00000 \\
\hline
\end{tabular}

An optimized maintenance system strategy needs to be unique and based on capitalizing strengths and mitigating weakness. It is always difficult to find the best maintenance system strategy. The strategy depends on the differences of purposes, the condition of resources and capabilities, and the 
existing organizational cultures. In this sense, selecting a maintenance system strategy is an MCDM problem. There are many works associated with maintenance system strategy provided valuable advices ranging from essential factors for a successful maintenance system strategy to the main obstacles of maintenance system strategy implementation. However, few works provided methods, which can evaluate and model the maintenance system strategy involved with several complex factors, systematically. Hence, this paper proposes an effective solution, which could help find suitable maintenance system strategy. As a test case, four biggest Iranian Vehicle Companies used for the proposed solution to logically deal with the complicated selection problem and provide a unique maintenance system strategy.

In order to realize the reason of the result of this maintenance system strategy selection and the usefulness of the proposed solution, this paper conducted a post-survey discussion with the maintenance system strategy committee of case companies. The discussion results are summarized as follows.

First, the committee chose C2 (cost) to be the most important criterion among a set of criteria. This choice is in a sense because "Top management support" is critical to all kinds of maintenance activities, not just maintenance strategy. Secondly, although many works on maintenance system strategy has suggested different strategies as the best, the committee chose A3 (TPM) to be the desired Maintenance System Strategy. The ranking of the strategies is as bellow: TPM, RCM, PM, PDM, CBM and CM.

\section{Conclusions}

As maintenance management is taking on an important strategic role, numerous companies are expecting their maintenance to be performed effectively in order to leverage and transform the maintenance into competitive advantages. More importantly, the successful maintenance management starts with a proper maintenance system strategy produced through a robust evaluation method. However, the maintenance strategy selection is a kind of MCDM problem, which requires considering a large number of complex factors as multiple evaluation criteria. Although numerous creditable works are devoted to the study of how to build a maintenance strategy and to execute it successfully, few of those have provided methods, which can systematically evaluate and model complex factors of the maintenance strategy.

To deal with the MCDM problem of this maintenance strategy selection, it is better to employ MCDM methods for reaching an effective solution. The ANP is a relatively new MCDM method, which can deal with all kinds of interactions systematically, unlike traditional MCDM methods, which are based on the independence assumption. Hence, this paper proposed a solution based on a combined ANP and DEMATEL approach to help companies evaluate and select maintenance strategies.

The results of this study show that the most desired purpose was "selection of optimized maintenance strategy", and "Total Productive Maintenance" was preferred. Because the proposed solution can handle the effects of dependences, it is relatively useful and makes the evaluation result to be more reasonable. Additionally, this study has contributed to extend practical applications of both ANP and DEMATEL in maintenance management field. Furthermore, using the suggested analytical procedure, it can effectively handle any problem of selection with multi-faceted factors. However, there are some limitations, such as the assessment scales of the ANP and the DEMATEL are not unified. Therefore, in order to promote and deepen continuing research in future, it is worthwhile to investigate more cases and exemplary companies in order to uncover invaluable new study issues. 


\section{References}

Al-Najjar, B., \& Alsyouf. I. (2003). Selecting the most efficient maintenance approach using fuzzy multiple criteria decision making. International Journal of Production Economics, 84, 85-100.

Agarwal. A., \& Shankar, R. (2002). Analyzing alternatives for improvement in supply chain performance. Work Study, 51(1), 32-38.

Bashiri. M., Badri. H., Hejazi. T.H. (2011). Selecting optimum maintenance strategy by FUZZY interactive linear assignment method. Applied mathematical modeling, 35, 152-164.

Bengtsson, M. (2004). Condition based maintenance system technology-where is development heading?, Proceedings of the 17th European Maintenance Congress, Barcelona, Spain, May, 1113.

Bevilacqua. M, \& Braglia, M. (2000). The analytic hierarchy process applied to maintenance strategy selection. Reliability Engineering and System Safety, 70, 71-83.

Blanchard, S.B (1997). An enhanced approach for implementation and total productive maintenance in manufacturing environment. Journal of Quality in Maintenance Engineering, 3(2), 69-80.

Byington. C., Roemer. M.J., \& Galie, T. (2002). Prognostic enhancements to diagnostic systems for improved condition- based maintenance, Proceedings of IEEE Aerospace Conference, 6, Big Sky, USA, March 9-16, 2815-2824.

Chand. G., \& Shirvani, B. (2000). Implementation of TPM in cellular manufacturing. Journal of Material Processing Technology, 103, 149-54.

Chung. S. H., Lee. A. H. I., \& Pearn, W. L. (2005). Analytic network process (ANP) approach for product mix planning in semiconductor fabricator. International Journal of Production Economics, 96(1), 15-36.

Coulter. K, \& Sarkis. J. (2005). Development of a media selection model using the analytic network process. International Journal of Advertising, 24(2), 193-216.

Djurdjanovic, D., Lee, J., \& Ni, J. (2003). Watchdog agenda infotronics based prognostics approach for product performance assessment and prediction. International Journal of Advanced Engineering Informatics, 17, 109-125.

Fontela. E., \& Gabus. A. (1976). The DEMATEL observer, DEMATEL 1976 Report, Switzerland Geneva: Battelle Geneva Research Center.

Gabus, A., \& Fontela, E. (1972). World problems and invitation to further thought within the framework of DEMATEL, Switzerland Geneva: Battelle Geneva Research Centre.

Gabus, A., \& Fontela, E. (1973). Perceptions of the World problematic: Communication procedure, communicating with those bearing collective responsibility (DEMATEL Report No. 1). Switzerland Geneva: Battelle Geneva Research Centre.

Hori. S., \& Shimizu, Y. (1999). Designing methods of human interface for supervisory control systems, Control Engineering Practice, 7(11), 1413-1419.

Kahraman. C., Ertay, T., \& Buyukozkan, G. (2006). A fuzzy optimization model for QFD planning process using analytic network approach. European Journal of Operational Research, 171(2), 390-411.

Karsak, E.E., \& Tolga, E. (2001). Fuzzy multi-criteria decision making procedure for evaluating advanced manufacturing system investments. International Journal of Production Economics, 69, 49-64.

Karsak. E. E., Sozer, S., \& Alptekin, S. E. (2003). Product planning in quality function deployment using a combined analytic network process and goal programming approach. Computers and Industrial Engineering. 44(1), 171-190.

Kinosita. E. (2003). From AHP to ANP. Operations Research of Japan, 48(9), 677-683.

Kumar, D., \& Kumar, P. (2005). FLM to select suitable maintenance strategy in process industries using MISO model. Journal of Quality in Maintenance Engineering, 11(4), 359-374.

Lee. J. W., \& Kim, S. H. (2001). An integrated approach for interdependent information system project selection. International Journal of Project Management, 19(2), 111-118. 
Leung. L. C., Hui, Y. V., \& Zheng, M. (2003). Analysis of compatibility between interdependent matrices in ANP. Journal of the Operational Research Society, 54(7), 758-768.

Li, J.R., Khoo, L.P., \& Tor, S.B. (2006). Generation of possible multiple components disassembly sequence for maintenance using a disassembly constraint graph. International Journal of Production Economics, 102, 51-65.

Mann. L., Saxena, A., \& Knapp, G.M. (1995). Statistical-based or condition-based preventive maintenance. Journal of Quality in Maintenance Engineering, 1(1), 46-59.

Mardani. N. (2010). Selecting suitable maintenance strategy by using FUZZY method (case study: Isfahan Siman Sepahan), MA thesis, Alammeh Tabatabaie university, Tehran.

McKone. K., Schroeder, R., \& Kristy, C. (1999). Total productive maintenance: a contextual view. Journal of Operations Management, 17, 123-44.

Meade. L. M., \& Presley, A. (2002). R\&D project selection using the analytic network process. IEEE Transactions on Engineering Management, 49(1), 59-66.

Mechefske, C.K., \& Wang, Z. (2001).Using fuzzy linguistics to select optimum maintenance and condition monitoring strategies. Mechanical System and Signal Processing, 15(6), 1129-1140.

Mechefske. C.K., \& Wang, Z. (2003). Using fuzzy linguistics to select optimum maintenance and condition monitoring strategies. Mechanical Systems and Signal Processing, 17(2), 305-316.

Mobley, R.K. (2002). An Introduction to Predictive Maintenance. $2^{\text {nd }}$ ed., Elsevier Science, New York.

Martorell, S., Sanchez, A., \& Serradell, V. (1999). Age-dependent reliability model considering effects of maintenance and working conditions. Reliability Engineering and System Safety, 64, 1931.

Nakajima. S (1988). Introduction to Total Productive Maintenance (TPM). Productivity Press, Cambridge, MA.

Niemira, M. P., \& Saaty, T. L. (2004). An analytic network process model for financial-crisis forecasting. International Journal of Forecasting, 20(4), 573-587.

Partovi, F. Y. (2001). An analytic model to quantify strategic service vision. International Journal of Service Industry Management, 12(5), 476-500.

Partovi, F. Y., \& Corredoira, R. A. (2002). Quality function deployment for the good of soccer. European Journal of Operational Research, 137(3), 642-656.

Partovi, F. Y. (2006). An analytic model for locating facilities strategically. Omega, 34(1), 41-55.

Saaty, T. L. (1996). The analytic network process-decision making with dependence and feedback. Pittsburgh, PA: RWS Publications.

Saaty, T. L. (1999). Fundamentals of the analytic network process. The International Symposium on the Analytic Hierarchy Process, Kobe, Japan.

Saaty, R. W. (2003). The analytic hierarchy process (AHP) for decision making and the analytic network process (ANP) for decision making with dependence and feedback. Creative Decisions Foundation.

Saaty, T. L. (2004). The analytic network process: Dependence and feedback in decision making (Part 1): Theory and validation examples, SESSION 4B: Theory and development of the analytic hierarchy process/analytic network process, In The 17th International Conference on Multiple Criteria Decision Making, August 6-11, 2004 at The Whistler Conference Centre, Whistler, British Columbia, Canada.

Sarkis, J. (1999). A methodological framework for evaluating environmentally conscious manufacturing programs. Computers and Industrial Engineering, 36(4), 793-810.

Sekitani, K., \& Takahashi, I. (2001). A unified model and analysis for AHP and ANP. Journal of the Operations Research Society of Japan, 44(1), 67-89.

Shang, J. S., Tjader, Y., \& Ding, Y. (2004). A unified framework for multi-criteria evaluation of transportation projects. IEEE Transactions on Engineering Management, 51(3), 300-313. 
Sharma, R.K., Kumar, D., \& Kumar, P. (2005). FLM to select suitable maintenance strategy in process industries using MISO model. Journal of Quality in Maintenance Engineering, 11(4), 359-374.

Shygith, K., Ilangkumaran, M., \& Kumanan, S. (2008). Multi-criteria decision making approach to evaluate optimum maintenance strategy in textile industry. Journal of Quality in Maintenance Engineering, 14(4), 375-386.

Swanson, L. (2001). Linking maintenance strategies to performance. International Journal of Production Economics, 70, 237-244.

Tesfamariam, D., \& Lindberg, B. (2005). Aggregate analysis of manufacturing systems using system dynamics and ANP. Computers and Industrial Engineering, 49(1), 98-117.

Waeyenbergh, G., Pintelon, L. (2002). A framework for maintenance concept development, International Journal of Production Economics, 77, 299-313.

Wang, Y., \& Hayfield, M. (1999). Rolling contact fatigue failure modes of lubricated silicon nitride in relation to ring crack defects. Wear, 225-229 (2), 1284-1292.

Wang, Y.J., \& Lee, H.S. (2007). Generalizing TOPSIS for fuzzy multiple-criteria group decisionmaking. Computers and Mathematics with Applications, 53, 1762-1772.

Yang, Y., Kurfess, T., Liang, S., \& Danyluk, S. (1999). Application of a specialized capacitance probe in bearing diagnosis, Wear, 225 (2), 1215-1221.

Yurdakul, M. (2004). AHP as a strategic decision-making tool to justify machine tool selection. Journal of Materials Processing Technology, 146(3), 365-376. 